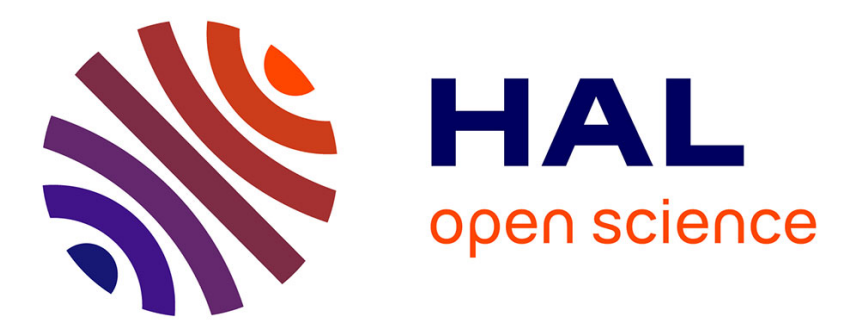

\title{
GENERATION OF HIGH POWER 20 fS PULSES
}

Patrick Georges, Franck Salin, Gilles Le Saux, Gérard Roger, Alain Brun

\section{To cite this version:}

Patrick Georges, Franck Salin, Gilles Le Saux, Gérard Roger, Alain Brun. GENERATION OF HIGH POWER 20 fs PULSES. Journal de Physique Colloques, 1988, 49 (C2), pp.C2-51-C2-54. 10.1051/jphyscol:1988212 . jpa-00227629

\section{HAL Id: jpa-00227629 https://hal.science/jpa-00227629}

Submitted on 1 Jan 1988

HAL is a multi-disciplinary open access archive for the deposit and dissemination of scientific research documents, whether they are published or not. The documents may come from teaching and research institutions in France or abroad, or from public or private research centers.
L'archive ouverte pluridisciplinaire HAL, est destinée au dépôt et à la diffusion de documents scientifiques de niveau recherche, publiés ou non, émanant des établissements d'enseignement et de recherche français ou étrangers, des laboratoires publics ou privés. 
JOURNAL DE PHYSIQUE

Colioque $\mathrm{C} 2$, Supplément au $n^{\circ} 6$, Tome 49 , juin 1988

GENERATION OF HIGH POWER 20 fS PULSES

P. GEORGES, F. SALIN, G. LE SAUX, G. ROGER and A. BRUN

Institut d'optique Théorique et Appliquée, CNRS-UA 14, Université Paris-Sud, F-91406 Orsay Cedex, France

RESUME - Nous présentons dans cet article la production d'impulsions de 20 fs très énergétiques (qq microjoules). Le spectre d'une impulsion de 80 fs est élargi par automodulation de phase dans une fibre optique monomode. L'impulsion est amplifiee dans un amplificateur à multipassages en utilisant un melange de colorant pour augmenter la bande d'amplification et ensuite compressée.

ABSTRACT - We describe the production of $20 \mathrm{fs}$, a few microjoules pulses using amplification in a multipass amplifier and compression of 80 fs pulses spectrally broadened by self-phase modulation in a monomode optical fiber. To improve the amplification bandwidth we have used a mixture of two dyes.

With the development of mode-locked lasers, the temporal resolution of physical phenomena kinetics measurements is limited by the laser pulse width. The compression of optical pulses spectrally broadened by self-phase modulation $/ 1 /$ is the method generally used to obtain the shortest pulses 12/. Recently, Fork et al. have reported the compression of optical pulses to six femtoseconds /3/. But unfortunately, the single mode fibers used limit the input peak power to a few hundred kilowatts. Moreover, the study of non-Iinear interactions induced by optical pulses needs high energy levels. These compressed pulses can not be used as a pump in such experiments. At this time, the temporal resolution is limited around $50 \mathrm{fs} / 4 /$ by the duration of the high peak power amplified pulses produced by the classical system containing a colliding pulse mode locked laser (CPM) and an amplifier. We report here the generation of $20 \mathrm{is}$ pulses with energy of a few microjoules by large bandwidth amplification of optical pulses spectrally broadened by self-phase modulation in a single mode fiber.

In our experiment, we have used optical pulses produced by a CPM 1 aser and amplified with a $3 \mathrm{~ns} N \mathrm{Nd} Y \mathrm{Yag}$ laser at a $10 \mathrm{~Hz}$ repetition rate to energies of about $1 \mathrm{~mJ}$. The pulses duration is 80 fs and their spectrum is centered at $615 \mathrm{~nm}$. A fraction of the pulse energy is coupled with a $20 \mathrm{x}$ microscope objective into a $15 \mathrm{~mm}$ long single mode fiber with a $4 \mu \mathrm{m}$ core diameter (Fig. 1). We estimate the intensity in the fiber close to $50 \mathrm{~kW}$.

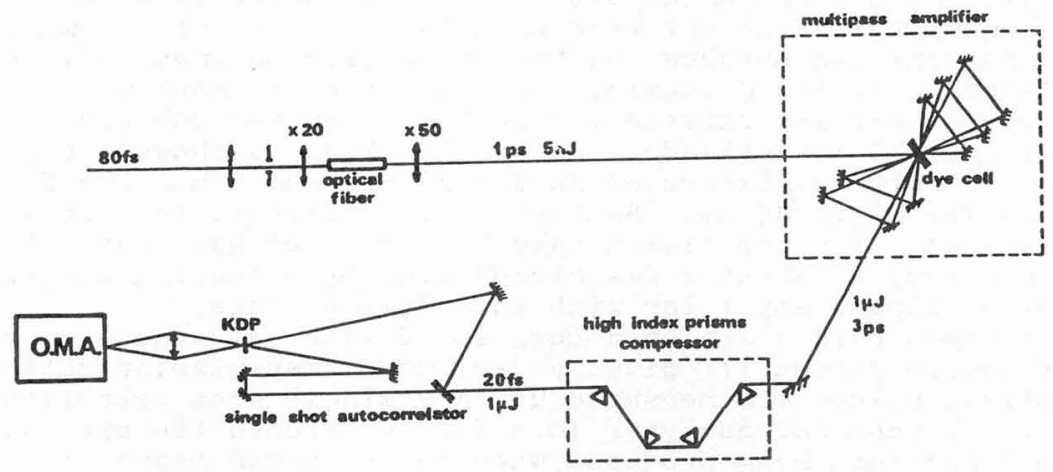

Figure 1 : Experimental set-up 
A typical pulse spectrum at the output of the fiber is shown in Fig. 2. One can see an asymmetrical shift of the spectrum towards the shorter wavelengths. At the fiber output, the pulse has been lengthened by group velocity dispersion and its duration is estimated to about 1 ps. The beam is then collimated with a $50 \mathrm{x}$ microscope objective. To increase the energy. we amplify the pulses before compression. In fact, long pulses make the amplification more efficient and limit non linear effects in this process. Furthermore, recent experiments using solid state amplifiers and linearly chirped pulses $15 \%$ have shown that the phase relation between the frequency components is conserved after the amplification allowing good compression ratios.

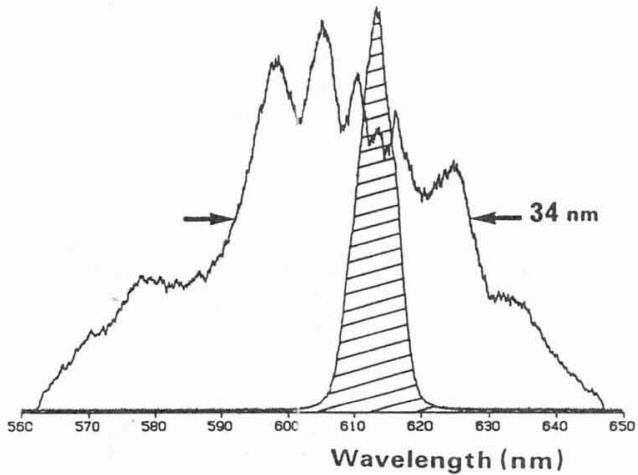

Figure 2 : Broadened pulse spectrum at the output of the fiber. The

input pulse peak power is estimated from the spectrum FWHM at $50 \mathrm{~kW}$.

The input spectrum is given as a comparison (hatched curve).

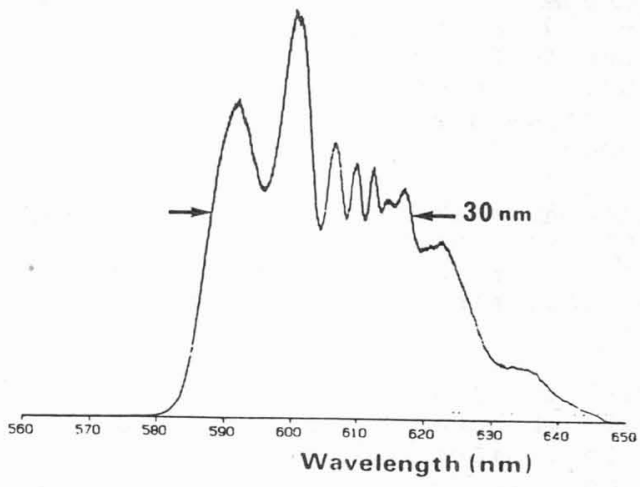

Figure 3 : Amplified pulse spectrum using a DCM (2 10-s $\mathrm{M} / \mathrm{I})$ and Rhodamine $610\left(2.10^{-5} \mathrm{M} / 1\right)$ mixture.

We use a multipass amplifier $/ 6 /$ to improve the gain efficiency. The pulse passes six times through a $5 \mathrm{~mm}$ dye cell pumped by a $20 \mathrm{~mJ}$, $3 \mathrm{~ns}$ pulse produced by a Nd:Yag laser (Fig. 1). The main problem is the choice of the amplifier dye. This dye must have a good efficiency in a large spectral band centered on the laser wavelength. In fact, the compressed pulse duration will be limited by the possibility of amplifying a large spectral band, where the chirp of the pulse is linear. We have studied several dyes to amplify the large output spectrum issued from the fiber and we have found that the amplification bandwidth was generaly shorter than the tuning curve of the dye as obtained in tunable dye laser. So we decided to mix two dyes to center and increase the bandwidth of the amplified spectrum. The problem is that the fluorescence of the first dye must not be absorbed by the second dye. Two dyes : Rhodamine 610 and DCM (4 Dicyanomethylene-2methyl-6p-dimethylaminostyryl-4h-pyxan) were used because they have complementary spectral bandwidths and because the DCM absorption maximum (481 $\mathrm{nm}$ ) is at a lower wavelength than the Rhodamine 610 fluorescence maximum (588 $\mathrm{nm})$. Dye concentrations were approximately $210^{-5} \mathrm{M} / 1$ for the DCM and 210 -s M/l for the Rhodamine 610 (dissolved in Methano1). Fig. 3 shows a typical amplified spectrum with a mixture of Rhodamine 610 and DCM. The full width at half maximum (FWHM) is $30 \mathrm{~nm}$. Because it is difficult to measure the energy of pulses at a low repetition rate $(10 \mathrm{~Hz})$, we have estimated the amplified pulses energy to about a few microjoules by measuring the efficiency gain of our multipass amplifier with this dyes mixture.

The amplified chirped pulses are then compressed with a sequence of four high index refraction prisms /7/ given a very good transmission ratio. The compressed optical pulses are measured using a single shot correlator /8/. With an optical multichannel analyzer (O.M.A.), we record the spatial profile of the second harmonic beam produced when two expanded beams cross in a $0.3 \mathrm{~mm}$ non-linear crystal (KDP). This system gives a real time visua- 
lization of the pulse autocorrelation and then allows us a precise adjustment of the prisms compressor. We regularly obtain single-shot autocorrelation functions, which correspond to pulses FWHM under $25 \mathrm{fs}$ (assuming a hyperbolic secant pulse shape). The shortest pulses obtained (Fig. 4) have a FWHM of $20 \mathrm{fs.} \mathrm{The} \mathrm{corresponding} \mathrm{spectral} \mathrm{width} \mathrm{as} \mathrm{seen} \mathrm{from} \mathrm{Fig.} 3$ is 30 $\mathrm{nm}$. For this spectral width (and a hyperbolic secant pulse shape), a minimum pulse width of 13 fs is possible, indicating that our pulses are close to the Fourier transform limit. One can see that the autocorrelation function presents wings. We think, that it corresponds to a non linear chirp which is not compensated by our compressor system. In fact, if the sequence of four high index refraction prisms is very compact and have a good transmission ratio, it presents a large negative cubic dispersion, leading to compressed pulses which present an oscillatory trailing edge /9/. We are presently studying a compressor containing two high tranmission gratings and two prisms to compensate the cubic dispersion and obtain high energy pulses without trailing eage.

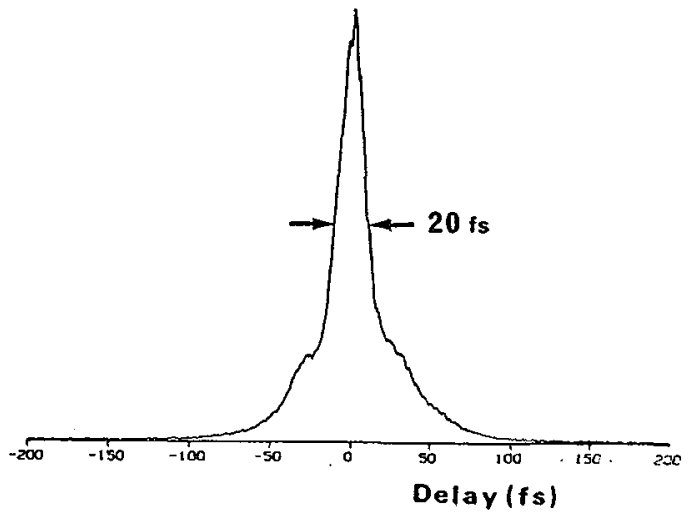

Figure 4 : single shot autocorrelation of a $20 \mathrm{fs}(50 \mathrm{MW})$ amplified and compressed pulse.

The stability of the compressed pulses directly depends on the spectral broadening in the optical fiber. By averaging twenty consecutives autocorrelation traces, we observe a broadening from 20 to 24 fs. This small broadening indicates a good shot to shot stability. Moreover we have also measured the beam divergence using a long focal lens $(2 \mathrm{~m})$ and a detector array. Results show the 20 fs pulses to be 1.1 times diffraction limited. Therefore it seems that the amplifier does not affect the spatial beam profile. This beam once focused could produce intensity in the range of $10^{15} \mathrm{~W} / \mathrm{cm}^{2}$. To prove the possibility of using these amplified ultrashort pulses in spectroscopic experiments, we have focused the beam in a $1 \mathrm{~mm}$ cell of water using a $35 \mathrm{~mm}$ lens. We then observed a spectral continuum extending from UV to IR with a very good pump depletion. The stability of the continuum was comparable to the one obtained using the initial 80 fs pulses. At this time, the study of several ultrafast effects is limited by the pump pulse duration. We think that the use of these ultrashort pulses can lead to a more comprehension of these effects.

In this paper, we present the generation of high energy 20 fs pulses. The broad spectrum produced in a single mode fiber by self-phase modulation is amplified in a multipass amplifier using a mixture of two dyes. The pulse energy is sufficient to create non-linear effects such as a continuum and so decrease our temporal resolution in spectroscopic experiments under 20 fs. To our knowledge these are the shortest amplified pulses produced at this time. 
This work is supported in part by the Ministère de la Recherche Scientifique and by the Direction des Recherches et Etudes Techniques (Division Optique).

\section{REFBRENCES}

/1/ R.R. Alfano and S.L. Shapiro, Phys. Rev. Lett. 24, 584 (1970).

/2/ W.J. Tomlinson, R.H. Stolen, and C.V. Shank, J. Opt. Soc. Am. B, 1. 139 (1984).

/3/ R.L. Fork, C.H. Brito Cruz, P.C. Becker, and C.V.: Shank, Opt. Lett. $12,483(1987)$.

14/ C.V. Shank, R.L. Fork, C.H. Brito Cruz, and W. Knox, in Ultrafast Phenomena V, G.R. Fleming and A.E. Siegman eds : (Springer-Verlag, Berlin, 1986), p. 179 .

/5/ D. Strickland, P. Majne, M. Bouvier, S. Williamson, and G. Mourou in Ultrafast Phenomena V, G.R. Fleming and A.E. Siegman, eds : (Springer Verlag, Berlin, 1986), p. 38 .

16/ M.M. Martin, E. Breheret, and Y.H. Meyex, Opt. Commun. 56, 61, (1985).

/7/ F. Salin, and A. Brun, J. Appl. Phys. 6, 4736, (1987).

$18 /$ F. Salin, P. Georges, G. Roger, and A. Brun, Appl. Opt., 26, 4528 (1987).

19/ C.H. Brito Cruz, P.C. Becker, R.L. Fork and C.V. Shank, Opt. Lett. 13. 123, (1988). 